\title{
Utjecaj mikrovalnog zagrijavanja i dodatka antioksidansa na održivost ekstra djevičanskog maslinovog ulja sorte Oblica
}

\section{Sažetak}

Djevičanskomaslinovouljeimavelikuotpornostpremaoksidacijskom kvarenju, zbogsastavatriacilglicerola s niskim udjelom polinezasićenih masnih kiselina i skupine fenolnih antioksidansa sastavljenih uglavnom od polifenola i tokoferola. $U$ ovom radu istraživan je utjecaj mikrovalnog zagrijavanja na oksidacijsku stabilnost ekstra djevičanskog maslinovog ulja, sa i bez dodatka antioksidansa i sinergista. Od prirodnih antioksidansa korišteni su ekstrakt ružmarina i ekstrakt zelenog čaja te sinergist limunska kiselina. Uzorci ulja sa i bez dodatka antioksidansa i sinergista zagrijavani su u mikrovalnoj pećnici kod konstante snage $300 \mathrm{~W}$ u različitom vremenskom periodu $(5,10,15$ i 20 minuta). Uzorci su također zagrijavani i kod različite snage uređaja $(180,300,450 W)$ u konstantnom vremenskom periodu 5 minuta. Rezultat testa ubrzane oksidacije ekstra djevičanskog maslinovog ulja izražen je peroksidnim brojem. Mikrovalnim zagrijavanjem uzoraka tijekom duljeg vremena zagrijavanja dolazi do porasta temperature i vrijednostiperoksidnog broja, odnosno dolazi do porasta oksidacijskog kvarenja ulja. Dodatkom antioksidansa i sinergista povećana je stabilnost ekstra djevičanskog maslinovog ulja. Najveća stabilnost ekstra djevičanskog maslinovog ulja postignuta je kombinacijom ekstrakta zelenog čaja i sinergista limunske kiseline.

Ključne riječi: ekstra djevičansko maslinovo ulje, mikrovalno zagrijavanje, oksidacijska stabilnost, antioksidansi, sinergisti

\section{Uvod}

Djevičansko maslinovo ulje, jedno je od rijetkih jestivih ulja koja se koriste bez bilo kakve kemijske obrade, ima veliku otpornost prema oksidacijskom kvarenju uglavnom zbog njegovog sastava masnih kiselina, prevladava visoki omjer mononezasićene - polinezasićene masne kiseline, također sadrži niz manjih spojeva snažne antioksidacijske aktivnosti među kojima se ističu polifenoli (Kiritsakis, 1990.). Maslinovo ulje je vrlo cijenjeno jestivo ulje kod ljudi na Mediteranu jer se konzumira bez procesa rafinacije, a zadržava svoju prirodnu aromu i miris. Također ima visoko cijenjene nutritivne karakteristike koje proizlaze iz uravnoteženog masno kiselinskog sastava (Boskow, 1996a.; Grande Covian, 1996.). Diskontinuirana proizvodnja ekstra djevičanskog maslinovog ulja ostvaruje se primjenom hidraulične preše pri čemu nema kondicioniranja sirovine niti primjene organskog otapala. Preradom ploda masline ovim postupkom prešanja osigurava se maksimalno zadržavanje aktivnih spojeva u ulju kao što su esencijalne masne kiseline, fenolne i flavonoidne tvari, tokoferoli, tokotrienoli, fitosteroli i dr. (Teh i Birch, 2013.) te zadržavanje karakterističnih senzorskih svojstva ulja. Tokoferoli i tokotrienoli su prirodna skupina spojeva u biljnim uljima koji imaju antioksidacijska svojstva te štite ulje od oksidacijskog kvarenja. U maslinovom ulju prevladava alfa oblik tokoferola što doprinosi dobroj oksidacijskoj stabilnosti ulja (Salvador, 2001.). Jestiva biljna ulja vrlo brzo podliježu nepoželjnim promjenama (kemijske reakcije, enzimski i mikrobiološki procesi) što rezultira kvarenjem ulja. Autooksidacija je najčešća vrsta kvarenja ulja, a 
može nastupiti brže ili sporije ovisno od procesa proizvodnje, sastava ulja, uvjeta skladištenja, prisutnosti sastojaka koji ubrzavaju ili usporavaju ovu reakciju (Martin-Polvillo, 2004.). Tijekom oksidacijskog kvarenja ulja dolazi do stvaranja primarnih i sekundarnih produkata oksidacije (Gray,1978; Rovellini, 1997.). Nastali produkti u malim količinama daju neugodan miris čime narušavaju senzorska svojstva ulja (Broadbent i Pike, 2003.). Poznavanje stabilnosti biljnih ulja je važno kako bi se moglo unaprijed utvrditi vrijeme za koje se može sačuvati od jače izražene oksidacije te za određivanje vremenskog roka upotrebe ulja. Brojna istraživanja oksidacijskog kvarenja biljnih ulja pokazuju da njihova održivost ovisi, prije svega, od vrste ulja odnosno sastava masnih kiselina te od vrste i udjela prirodnih antioksidansa u ulju. Frega i sur. (1999.) utvrđuju da slobodne masne kiseline u biljnom ulju djeluju kao prooksidansi, ubrzavaju oksidacijsko kvarenje ulja te kod većeg udjela smanjuju stabilnost ulja. U praksi se primjenjuju metode za određivanje oksidacijske stabilnosti biljnih ulja temeljene na ubrzanoj oksidaciji: Oven test, AOM test i Rancimat test (Shahidi, 2005.; Suja, 2004.; Abramović, 2006.; Farhoosh, 2008.). Stabilnost biljnih ulja može se poboljšati dodatkom antioksidansa, a to su tvari koje usporavaju proces autooksidacije. Poznati su sintetski i prirodni antioksidansi koji se koriste u kombinaciji sa sinergistima (limunska kiselina) za stabilizaciju biljnih ulja radi povećanja otpornosti prema oksidaciji (Alavi i Golmakani, 2017.; Yanishlieva i Marinova, 2001.; Merrill, 2008.). Danas je trend istraživanje raznih biljnih materijala (začinske biljke) koji sadrže aktivne sastojke kao što su fenolni spojevi te pokazuju značajno antioksidacijsko djelovanje u biljnim uljima (Zunin i sur., 2010.; Berra, 2006.; Velasco i Dobarganes, 2002.; Bandoniene, 2000.). Stabilizacija hladno prešanih ulja usmjerena je na primjenu ekstrakata začinskih biljaka (ružmarina, zelenog čaja, kadulje, origana i dr.) u svrhu zaštite od oksidacijskog kvarenja (Taghvaei i Jafari, 2013.; Pan, 2007.; Ahn, 2008.). Erkan i sur. (2008.) istražuju antioksidacijsku aktivnost ekstrakta ružmarina i drugih spojeva na stabilizaciju ulja. Gramza i sur. (2006.) izvještavaju da visoku antioksidacijsku aktivnost, mjerenu kao indukcijski period, pokazuje etanolni ekstrakt zelenog čaja u odnosu na aktivnost BHT i ekstrakta crnog čaja u suncokretovom ulju. Hraš i sur. (2000.) ukazuju na antioksidacijski i sinergistički efekat ekstrakta ružmarina i alfa tokoferola kod stabilizacije suncokretovog ulja. U različitim procesima prehrambene industrije primjenjuje se mikrovalno zagrijavanje pri čemu zagrijavanje materijala nastaje zbog pretvorbe energije elektromagnetskih valova u toplinu u materijalima koji posjeduju dielektrična svojstva. U materijalima koji imaju električne dipole (molekule) koje izložene djelovanju elektromagnetskog polja polariziraju, dolazi do trenja molekula i stvaranja topline. (Lovrić, 2003.). Temperatura uljne faze se dvostruko brže povećava tijekom mikrovalnog zagrijavanja u odnosu na temperaturu vode ili vodenog dijela hrane (Barringer, 1995.). U jestivim biljnim uljima tijekom mikrovalnog tretiranja dolazi do oksidacijskih promjena (Dostalova, 2005.; Hassanein, 2003.; Biswas, 2007; Chiavaro, 2010.; Erkan, 2009.), pri čemu nastaju slobodni radikali u većoj količini, a pri visokim temperaturama moguća je i izomerizacija te formiranje trans izomera (Albi i sur., 1997.). Stupanj oksidacijskog kvarenja ulja djelovanjem mikrovalnog zagrijavanja ovisi o udjelu polinezasićenih masnih kiselina, a rezultat kvarenja je porast vrijednosti slobodnih masnih kiselina (Sumnu, 2001.; Yoshida, 1993.). Ovim tretiranjem i zagrijavanjem smanjuje se održivost ili oksidacijska stabilnost ulja, a trigliceridi i digliceridi su skloni toplinskoj hidrolizi, osobito u prisutnosti vode. Mikrovalno zagrijavanje dovodi do povećane razgradnje nutritivnih spojeva kao što su vitamini, esencijalne masne kiseline i fenoli (Oomah i sur., 1998.).

Cilj istraživanja ovog rada bio je ispitati utjecaj procesnih parametara mikrovalnog zagrijavanja (vrijeme zagrijavanja, snaga uređaja) na oksidacijsku stabilnost ili održivost ekstra djevičanskog maslinovog ulja. Na ovom ulju ispitivan je i utjecaj dodatka prirodnih antioksidansa $\mathrm{i}$ sinergista na promjenu stabilnosti ulja. 


\section{Materijal i metode}

Ispitivanje utjecaja parametara mikrovalnog zagrijavanja i dodatka antioksidanasa na održivost provedeno je s ekstra djevičanskim maslinovim uljem sorte Oblica proizvedenim na obiteljskom poljoprivrednom gospodarstvu na otoku Ugljanu kod Zadra. Utjecaj dodatka prirodnih antioksidanasa na oksidacijsku stabilnost ovog ulja proveden je $s$ ekstraktom ružmarina tip StabilEnhance"OSR $(0,15 \%)$ i ekstraktom zelenog čaja $(0,15 \%)$ te sinergistom limunskom kiselinom $(0,01 \%)$.

StabilEnhance OSR je ekstrakt ružmarina u formulaciji viskozne tekućine, dobiven od listova ružmarina koje ima botaničko ime Romarinus officinalis $L$, topljiv je u vodi i ulju. Specifikacija ovog ekstrakta ružmarina: udjel karnosolne kiseline min. $5 \%$, proizvođač Naturex, Francuska.

Ekstrakt zelenog čaja proizveden je iz lišća biljke Camellia sinensis L. Specifikacija ekstrakta zelenog čaja: udjel epigalokatehin galata (EGCG) je $>45 \%$, udjel ukupnih polifenola $>98 \%$, udjel kofeina $<0,5 \%$, udjel katehina $>80 \%$, proizvođač Naturex, Francuska.

Limunska kiselina je bijela kristalna tvar u obliku praha, topljiva u vodi, proizvođač T.T.T. d.o.o., Hrvatska.

\section{Određivanje osnovnih parametara kvalitete ulja}

$\mathrm{Na}$ ispitivanom ekstra djevičanskom maslinovom ulju određeni su osnovni parametri kvalitete: peroksidni broj i slobodne masne kiseline primjenom standardnih metoda.

\section{Slobodne masne kiseline}

Slobodne masne kiseline (SMK) u ispitivanom ekstra djevičanskom maslinovom ulju određene su standardnom metodom (ISO 660: 1996) koja se temelji na principu titracije sotopinom natrij-hidroksida. Rezultat je prikazan kao udjel (\%) slobodnih masnih kiselina izražen kao oleinska kiselina prema jednadžbi:

$$
\text { SMK ( } \% \text { oleinske kiseline })=V \cdot C \cdot M / 10 \cdot m
$$

$\mathrm{V}=\mathrm{utrošak}$ otopine natrij-hidroksida za titraciju uzorka $(\mathrm{mL})$;

$c=$ koncentracija otopine natrij-hidroksida za titraciju, $c(N a O H)=0,1 \mathrm{~mol} / \mathrm{L}$;

$\mathrm{M}=$ molekulska masa oleinske kiseline, $\mathrm{M}=282 \mathrm{~g} / \mathrm{mol}$;

$\mathrm{m}=$ masa uzorka ulja za ispitivanje (g).

\section{Peroksidnibroj}

Peroksidni broj (Pbr) je pokazatelj stupnja oksidacijskog kvarenja jestivih biljnih ulja, a njegovo određivanje je najviše primjenjivana metoda za ispitivanje primarnih produkata oksidacije ulja (hidroperoksidi, peroksidi). Peroksidni broj ispitivanog ulja određen je standardnom metodom (ISO 3960:2007). Rezultat je izražen kao mmol aktivnog kisika koji potječe iz nastalih peroksida prisutnih u $1 \mathrm{~kg}$ ulja. Vrijednost se izračunava prema jednadžbi:

$$
\mathrm{Pbr}=\left(\mathrm{V}_{1}-\mathrm{V}_{0}\right) \cdot 5 / \mathrm{m} \quad\left(\mathrm{mmol} \mathrm{O}_{2} / \mathrm{kg}\right)
$$

$\mathrm{V}_{1}=$ volumen otopine natrij-tiosulfata, $\mathrm{c}\left(\mathrm{Na}_{2} \mathrm{~S}_{2} \mathrm{O}_{3}\right)=0,01 \mathrm{~mol} / \mathrm{L}$ utrošen za titraciju uzorka ulja (mL);

$\mathrm{V}_{0}=$ volumen otopine natrij-tiosulfata utrošen za titraciju slijepe probe $(\mathrm{mL})$;

$\mathrm{m}=$ masa uzorka ulja $(\mathrm{g})$. 


\section{Određivanje oksidacijske stabilnosti ulja}

Poznavanje održivosti ili oksidacijske stabilnosti jestivih biljnih ulja važno je kako bi se unaprijed odredio vremenski period za koji se mogu sačuvati od jače izraženog oksidacijskog kvarenja, bez bitnih promjena kvalitete.

\section{Mikrovalno zagrijavanje}

Priprema uzoraka ekstra djevičanskog maslinovog ulja, sa i bez dodatka antioksidansa i sinergista, za analizu utjecaja mikrovalnog zagrijavanja na oksidacijsku stabilnost provedena je tako da se $50 \mathrm{~g}$ ulja stavilo u petrijeve zdjelice promjera $9 \mathrm{~cm}$, te se postavljaju u mikrovalnu pećnicu kod određene razine izlazne snage i vremena trajanja tretiranja. Ispitivani pojedini prirodni antioksidans stavi se u čašu s maslinovim uljem, zagrijava na temperaturi $60-70{ }^{\circ} \mathrm{C}$ uz konstantno miješanje. $U$ ispitivanju korištena je mikrovalna pećnica firme Samsung Electronics, model MW73E, izlazne razine snage $100 \mathrm{~W}-800 \mathrm{~W}$. Kada se izvadi uzorak ulja iz pećnice izmjeri se temperatura tretiranog ulja, izdvoji se uzorak od $1 \mathrm{~g}$ ulja u tikvicu za određivanje peroksidnog broja (Pbr) kao pokazatelja stupnja oksidacije ulja. Postignuta temperatura tretiranog ulja se mjeri digitalnim termometrom Ama-digit, model AD13TH, područje mjerenja od - 35 do $300^{\circ} \mathrm{C}$, firme Amarell Electronic, Njemačka.

\section{Utjecaj jačine zagrijavanja (snage uređaja)}

Ispitivano ekstra djevičansko maslinovo ulje se zagrijava u mikrovalnoj pećnici kod različitih izlaznih snaga rada uređaja ( $180 \mathrm{~W}, 300 \mathrm{~W}, 450 \mathrm{~W})$ u vremenu tretiranja 5 minuta. Za svaku korištenu sljedeću snagu rada pećnice uzima se drugi uzorak maslinovog ulja.

\section{Utjecaj vremena zagrijavanja}

Ekstra djevičansko maslinovo ulje se zagrijava u mikrovalnoj pećnici kod snage $300 \mathrm{~W}$ u različitim vremenima trajanja tretiranja $(5,10,15,20$ minuta). Uzorak ulja se nakon $5 \mathrm{~min}$. tretiranja kod ove snage uređaja izvadi iz pećnice, izmjeri temperatura i uzme uzorak za određivanje peroksidnog broja, ponovo se vraća u pećnicu te zagrijava narednih $5 \mathrm{~min}$. i tako do ukupnog vremena tretiranja 20 minuta. Dakle, oksidacijska stabilnost uzoraka ulja prikazuje se kao vrijednost peroksidnog broja (Pbr) određivana svakih 5 minuta tijekom zagrijavanja u trajanju 20 minuta kod konstantne snage uređaja.

\section{Rezultati i rasprava}

Parametri kvalitete ulja

Osnovni parametri kvalitete ekstra djevičanskog maslinovog ulja peroksidni broj (Pbr) i slobodne masne kiseline (SMK) prikazani su u Tablici 1. Izračunate vrijednosti ovih parametara ukazuju na to da je maslinovo ulje dobre kvalitete jer su ispitivani parametri u skladu s Pravilnikom o uljima od ploda i komine maslina (NN 7/2009).

Tablica 1. Kemijske karakteristike ekstra djevičanskog maslinovog ulja sorte Oblica

Table 1 Chemical characteristics of extra virgin olive oil of Oblica cultivar

\begin{tabular}{|c|c|}
\hline $\begin{array}{c}\mathrm{Pbr} \\
\left(\mathrm{mmol} \mathrm{O}_{2} / \mathrm{kg}\right)\end{array}$ & 6,34 \\
\hline $\begin{array}{c}\text { SMK } \\
\text { ( \% oleinske kiseline) }\end{array}$ & 0,20 \\
\hline
\end{tabular}




\section{Oksidacijska stabilnost}

Rezultati ispitivanja utjecaja mikrovalnog zagrijavanja te dodatka prirodnih antioksidansa i sinergista na oksidacijsku stabilnost ekstra djevičanskog maslinovog ulja prikazani su u Tablicama 2 i 3.

U Tablici 2. prikazan je utjecaj vremena mikrovalnog zagrijavanja (5, 10, 15 i 20 minuta), kod konstantne snage uređaja $300 \mathrm{~W}$ te dodatka prirodnih antioksidansa i sinergista na oksidacijsku stabilnost ekstra djevičanskog maslinovog ulja. Stupanj oksidacijskog kvarenja prikazan je peroksidnim brojem (Pbr). Mikrovalnim zagrijavanjem maslinovog ulja bez dodatka antioksidansa i sinergista (kontrolni uzorak) u navedenom vremenskom periodu zapažen je postepeni porast vrijednosti peroksidnog broja. Nakon 20 min zagrijavanja ulja dobivena je vrijednost $\mathrm{Pbr}$ od $9,25 \mathrm{mmol} \mathrm{O}_{2} / \mathrm{kg}$. Dodatkom prirodnog antioksidansa ekstrakta ružmarina tip StabilEnhance $(0,15 \%)$ u maslinovo ulje dovelo je do sniženja vrijednosti Pbr tijekom zagrijavanja mikrovalovima u vremenskom periodu 5-20 minuta, nakon 20 min tretiranja ulja Pbr ima vrijednost $8,74 \mathrm{mmolO}_{2} / \mathrm{kg}$ u odnosu na kontrolni uzorak. Ovo sniženje Pbr u odnosu na kontrolni uzorak ulja pokazuje da ovaj antioksidans štiti ulje od oksidacijskog kvarenja. Kombinacijom ekstrakta ružmarina i sinergista $(0,01 \%$ limunske kiseline) ne dovodi do daljnjeg porasta stabilnosti maslinovog ulja, nakon 20 min mikrovalnog zagrijavanja Pbr je 9,0 mmol O $/ \mathrm{kg}$. Primjenom prirodnog antioksidansa ekstrakta zelenog čaja $(0,15 \%)$ postiže se veća stabilnost maslinovog ulja odnosno veća je otpornost ulja prema oksidacijskom kvarenju. Nakon 20 min mikrovalnog zagrijavanja Pbr je $8,50 \mathrm{mmol} \mathrm{O}_{2} / \mathrm{kg}$. Kombinacijom ekstrakta zelenog čaja i sinergista limunske kiseline ostvarena je još veća stabilnost maslinovog ulja prema oksidacijskom kvarenju u uvjetima ovog testa. Nakon 20 min zagrijavanja ulja mikrovalovima dobivena je vrijednost $\mathrm{Pbr} 8,33 \mathrm{mmol} \mathrm{O}_{2} / \mathrm{kg}$. U ovom slučaju vidimo da dodatak sinergista dodatno usporava oksidacijsko kvarenje ovog ulja. Dakle, ostvarena je sinergija ekstrakta zelenog čaja i limunske kiseline u navedenim koncentracijama.

Tablica 2. Utjecaj vremena i temperature mikrovalnog zagrijavanja, kod snage $300 \mathrm{~W}$, na oksidacijsku stabilnost ekstra djevičanskog maslinovog ulja, sa i bez dodatka antioksidansa i sinergista.

Table 2 Effect of time and temperature of microwave heating at $300 \mathrm{~W}$, on the oxidation stability of extra virgin olive oil with and without the addition of antioxidants and synergists.

\begin{tabular}{|c|c|c|c|c|c|c|}
\hline \multirow{2}{*}{ Uzorci/Samples } & \multirow{2}{*}{\multicolumn{2}{|c|}{$\begin{array}{c}\text { Antioksidans/ Antioxidant } \\
\text { (\%) }\end{array}$}} & \multicolumn{4}{|c|}{$\begin{array}{l}\text { Vrijeme mikrovalnog zagrijavanja/ } \\
\text { Microwave heating time (min) }\end{array}$} \\
\hline & & & 5 & 10 & 15 & 20 \\
\hline \multirow{2}{*}{$\begin{array}{l}\text { Ekstra djevičansko } \\
\text { maslinovo ulje } \\
\text { (kontrolni uzorak) }\end{array}$} & \multirow{2}{*}{-} & $\mathrm{T}\left({ }^{\circ} \mathrm{C}\right)$ & 76 & 101 & 125 & 122 \\
\hline & & $\mathrm{Pbr}\left(\mathrm{mmol} \mathrm{O}_{2} / \mathrm{kg}\right)$ & 8,50 & 8,81 & 9,09 & 9,25 \\
\hline \multirow{2}{*}{$\begin{array}{l}\text { Ekstrakt ružmarina } \\
\text { (StabilEnhance) }\end{array}$} & \multirow[b]{2}{*}{$0,15 \%$} & $\mathrm{~T}\left({ }^{\circ} \mathrm{C}\right)$ & 96 & 128 & 138 & 145 \\
\hline & & $\mathrm{Pbr}\left(\mathrm{mmol} \mathrm{O}_{2} / \mathrm{kg}\right)$ & 6,37 & 7,93 & 8,59 & 8,74 \\
\hline \multirow{2}{*}{$\begin{array}{l}\text { Ekstrakt ružmarina } \\
\text { (StabilEnhance) + } \\
\text { limunska kiselina }\end{array}$} & \multirow{2}{*}{$\begin{array}{c}0,15 \% \\
+ \\
0,01 \%\end{array}$} & $\mathrm{~T}\left({ }^{\circ} \mathrm{C}\right)$ & 85 & 125 & 134 & 130 \\
\hline & & $\mathrm{Pbr}\left(\mathrm{mmol} \mathrm{O}_{2} / \mathrm{kg}\right)$ & 6,75 & 8,18 & 8,75 & 9,00 \\
\hline \multirow[b]{2}{*}{ Ekstrakt zelenog čaja } & \multirow[b]{2}{*}{$0,15 \%$} & $\mathrm{~T}\left({ }^{\circ} \mathrm{C}\right)$ & 100 & 114 & 139 & 136 \\
\hline & & $\mathrm{Pbr}\left(\mathrm{mmol} \mathrm{O}_{2} / \mathrm{kg}\right)$ & 6,31 & 7,45 & 8,25 & 8,50 \\
\hline \multirow{2}{*}{$\begin{array}{l}\text { Ekstrakt zelenog čaja } \\
+ \text { limunska kiselina }\end{array}$} & \multirow{2}{*}{$\begin{array}{c}0,15 \% \\
+ \\
0,01 \% \\
\end{array}$} & $\mathrm{~T}\left({ }^{\circ} \mathrm{C}\right)$ & 93 & 120 & 139 & 149 \\
\hline & & $\mathrm{Pbr}\left(\mathrm{mmol} \mathrm{O}_{2} / \mathrm{kg}\right)$ & 6,25 & 7,20 & 8,00 & 8,33 \\
\hline
\end{tabular}


U Tablici 3. vidljivi su rezultati ispitivanja utjecaja snage uređaja (180, 300, 450W) mikrovalne pećnice te dodatka prirodnih antioksidansa i sinergista na oksidacijsku stabilnost ekstra djevičanskog maslinovog ulja. Mikrovalnim zagrijavanjem, kontrolnog uzorka, kod snage 180 W tijekom 5 minuta tretiranja dobivena je vrijednost peroksidnog broja 7,83 $\mathrm{mmolO}_{2} / \mathrm{kg}$. Povećanjem snage mikrovalne pećnice na $300 \mathrm{~W}$ i $450 \mathrm{~W}$ dolazi do povećanja temperature ulja što ujedno dovodi i do porasta Pbr. I kod ovog ispitivanja dodatkom ekstrakta zelenog čaja $(0,15 \%)$ stvorena je bolja zaštita ulja od oksidacijskog kvarenja u odnosu na primjenu ekstrakta ružmarina (StabilEnhance) iste koncentracije. Također se zapaža pojava da dodatak sinergista limunske kiseline $(0,01 \%)$ u kombinaciji s dodatkom ekstrakta zelenog čaja dovodi do bolje zaštite ulja od oksidacije, nakon mikrovalnog zagrijavanja ulja kod snage $450 \mathrm{~W}$ vrijednost Pbr je $8,01 \mathrm{mmolO}_{2} / \mathrm{kg}$. Navedeni sinergist u kombinaciji s ekstraktom ružmarina ne postiže veću stabilnost maslinovog ulja u odnosu na uzorak s tim antioksidansom ali bez sinergista.

Tablica 3. Utjecaj snage mikrovalnog zagrijavanja, kod 5 minuta tretiranja, na oksidacijsku stabilnost ekstra djevičanskog maslinovog ulja, sa i bez dodatka antioksidansa i sinergista.

Table 3 Effects of microwave power up to 5 minutes of treatment on the oxidative stability of extra virgin olive oil with and without the addition of antioxidants and synergists.

\begin{tabular}{|c|c|c|c|c|c|}
\hline \multirow{2}{*}{ Uzorci/Samples } & \multicolumn{2}{|c|}{ Antioksidans/ Antioxidant (\%) } & \multicolumn{3}{|c|}{$\begin{array}{l}\text { Snaga mikrovalnog zagrijavanja/ } \\
\text { The power of microwave heating (W) }\end{array}$} \\
\hline & & & 180 & 300 & 450 \\
\hline \multirow{2}{*}{$\begin{array}{l}\text { Ekstra djevičansko } \\
\text { maslinovo ulje } \\
\text { (kontrolni uzorak) }\end{array}$} & \multirow{2}{*}{ - } & $\mathrm{T}\left({ }^{\circ} \mathrm{C}\right)$ & 65 & 76 & 120 \\
\hline & & $\mathrm{Pbr}\left(\mathrm{mmol} \mathrm{O}_{2} / \mathrm{kg}\right)$ & 7,83 & 8,50 & 8,96 \\
\hline \multirow{2}{*}{$\begin{array}{l}\text { Ekstrakt ružmarina } \\
\text { (StabilEnhance) }\end{array}$} & \multirow{2}{*}{$0,15 \%$} & $\mathrm{~T}\left({ }^{\circ} \mathrm{C}\right)$ & 62 & 96 & 120 \\
\hline & & $\mathrm{Pbr}(\mathrm{mmol} \mathrm{O} / \mathrm{kg})$ & 6,25 & 6,37 & 8,41 \\
\hline \multirow{2}{*}{$\begin{array}{c}\text { Ekstrakt ružmarina } \\
\text { (StabilEnhance) } \\
+ \\
\text { limunska kiselina }\end{array}$} & \multirow{2}{*}{$\begin{array}{c}0,15 \% \\
+ \\
0,01 \%\end{array}$} & $\mathrm{~T}\left({ }^{\circ} \mathrm{C}\right)$ & 67 & 85 & 128 \\
\hline & & $\mathrm{Pbr}\left(\mathrm{mmol} \mathrm{O}_{2} / \mathrm{kg}\right)$ & 6,25 & 6,75 & 8,58 \\
\hline \multirow{2}{*}{$\begin{array}{l}\text { Ekstrakt zelenog } \\
\text { čaja }\end{array}$} & \multirow{2}{*}{$0,15 \%$} & $\mathrm{~T}\left({ }^{\circ} \mathrm{C}\right)$ & 69 & 100 & 135 \\
\hline & & $\mathrm{Pbr}\left(\mathrm{mmol} \mathrm{O}_{2} / \mathrm{kg}\right)$ & 6,25 & 6,31 & 8,25 \\
\hline Ekstrakt zelenog & \multirow{2}{*}{$\begin{array}{c}0,15 \% \\
+ \\
0,01 \%\end{array}$} & $\mathrm{~T}\left({ }^{\circ} \mathrm{C}\right)$ & 67 & 93 & 126 \\
\hline $\begin{array}{c}+ \\
\text { limunska kiselina }\end{array}$ & & $\mathrm{Pbr}\left(\mathrm{mmol} \mathrm{O}_{2} / \mathrm{kg}\right)$ & 6,25 & 6,25 & 8,01 \\
\hline
\end{tabular}




\section{Zaključak}

Na temelju ispitivanja utjecaja procesnih parametara mikrovalnog zagrijavanja te dodatka prirodnih antioksidansa i sinergista limunske kiseline mogu se izvesti sljedeći zaključci. Vrijeme trajanja mikrovalnog zagrijavanja utječe na oksidacijsku stabilnost ekstra djevičanskog maslinovog ulja. Porastom vremena tretiranja ulja mikrovalovima od 5 do 20 minuta, kod snage uređaja 300W, postepeno se povećava peroksidni broj i temperatura ulja. Snaga mikrovalne pećnice utječe na oksidacijsko kvarenje ekstra djevičanskog maslinovog ulja. Porastom snage sa $180 \mathrm{~W}$ na $300 \mathrm{~W}$ i $450 \mathrm{~W}$ u vremenu tretiranja mikrovalnim zagrijavanjem od 5 minuta povećava se peroksidni broj i temperatura ulja. Ispitivani prirodni antioksidansi (ekstrakt ružmarina tip StabilEnhance, ekstrakt zelenog čaja) povećavaju zaštitu ekstra djevičanskog maslinovog ulja od oksidacijskog kvarenja. Najveća stabilnost ekstra djevičanskog maslinovog ulja postignuta je kombinacijom ekstrakta zelenog čaja i sinergista limunske kiseline.

\section{Literatura}

Abramović, H., Abram, H. (2006) Effect of added rosemary extract on oxidative stability of Camelina sativa oil. Acta agriculturae Slovenica, 87 (2), 255-261.

Ahn, J.-H., Kim, Y.-P., Seo, E.-M., Choi, Y.-K., Kim, H.-S. (2008) Antioxidant effect of natural plant extracts on the microencapsulated high oleic sunflower oil. Journal of Food Engineering, 84, 327-334.

Alavi, N., Golmakani, M.T. (2017) Improving oxidative stability of olive oil: Incorporation of Spirulina and evaluation of its synergism with citric acid. Grasas Y Aceites, 68 (1), 1-11.

Albi, T., Lanzon, A., Guinda, A., Leon, M., Perez-Camino, C.M. (1997) Microwave and conventional heating effects on thermoxidative degradation of edible fats. Journal of Agricultural Food Chemistry, 45 (10), 3795-3798.

Bandoniene, D., Pukalskas, A., Venskutonis, P.R. and Gruzdiene (2000) Preliminary screening of antioxidant activity of some plant extracts in rapeseed oil. Food Res. Int., 33, 785-791.

Barringer, S.A. (1995) Experimental and predictive heating rates of microwave food systems. Dissertation Abstracts International $B, 55,4188$.

Berra, D., Lahiri, D., Nag, A. (2006) Studies on a natural antioxidant for stabilization of edible oil and comparasion with synthetic antioxidant. J. Food Eng., 74, 542-545.

Broadbent, C.J., Pike, O.A. (2003) Oil stability indeks correlated with sensory determination of oxidative stability in canola oil. Journal of the American Oil Chemists Society, 80, 59-63.

Biswas, A., Adhvaryu, A., Stevenson, D.G., Sharma, B.K., Willet, J.L., Erhan, S.Z. (2007) Microwave irradiation effects on the structure, viscosity, thermal properties and lubricity of soybean oil. Industrial Crops and Products, 25, 1-7.

Boskow, D. (1996a) Changes caused by enzymes and oxidation. In D. Boskow, Olove oil: Chemistry and technology pp. 96-100. Champaign, IL, USA, AOCS Press.

Chiavaro, E., Rodriguez-Estrada, M.T., Vittadini, E., Pellegrini, N. (2010) Microwave heating of different vegetable oils: Relation between chemical and thermal parameters. LWT-Food Science and Technology, 43, 1104-1112.

Dostalova, J., Hanzlik, P., Reblova, Z., Pokorny, J. (2005) Oxidative Changes of Vegetable Oils during Microwave Heating. Czech. J. Food Sci., 23 (6), 230-239.

Erkan, N., Ayranci, G., Ayranci, E. (2008) Antioxidant activities of rosemary (Rosmarinus Officinalis L.) extract blackseed (Nigella sativa L.) essential oil, carnosic acid, rosmarinic acid and sesamol. Food Chem., 110, 76-82.

Erkan, N., Ayranci, G., Ayranci, E. (2009) A kinetic study of oxidation development in sunflower oil under microwave heating: Effect of natural antioxidants. Food research Internatioanal, 42, 1171-1177.

Farhoosh, R., Niazmand, R., Rezaei, M., Sarabi, M. (2008) Kinetic parameter determination of vegetable oil oxidation under Rancimat test conditions. European Journal of Lipid Science and Technology, 110 (6), 587-592.

Frega, N., Mozzon, M., Lercker, G. (1999) Effect of Free Fatty Acids on Oxidative Stability of Vegetable Oil. Journal of the American Oil Chemists Society, 76 (3), 325-329.

Gramza, A., Khokhar, S., Yoko, S., Gliszczynska-Swiglo, A., Hes, M., Korczak, J. (2006) Antioxidant activity of tea extracts in lipids and correlation with polyphenol content. European Journal of Lipid Science and Technology, 108, 351362.

Grande Covian, F. (1996) Nutricion y valor biologco. In Enciclopedia mundial del olivo. Consejo Oleicola Intrernacional pp. 345-367, Barcelona: Plaza y Janes Editiores SA.

Gray, J.I. (1978) Measurement of lipid oxidation: a review. Journal of the American Oil Chemists Society, 55, $539-546$.

Hassanein, M.M., El-Shami, S.M., El-Mallah, M.H. (2003) Changes occurring in vegetable oils composition due to microwave heating. Grasas y Aceites, 54, 343-349.

Hraš, A. R., Hadolin, M., Knez, Ž., Bauman, D. (2000) Comparasion of antioxidative and synergistic effects of rosemary extract with a - tocopherol, assorbyl palmitate and citric acid in sunflower oil. Food Chem., 71, $229-233$.

Yanishlieva, Nedyalka V., Marinova, Emma M. (2001) Stabilisation of edible oils with natural antioxidants. European Journal of Lipid Science and Technology, 103, 752-767.

Yoshida, H. (1993) Influenceof fatty acids of different unsaturation int he oxidation of purified vegetable oils during microwave irradiation. J. Sci. Food Agric., 62, 41-47.

Kiritsakis, A.K.: Olive Oil. AOCS Press, Champaign, IL (USA) 1990.

Lovrić, T. (2003) Procesi u prehrambenoj industriji s osnovama prehrambenog inženjerstva. Zagreb: Hinus.

Martin-Polvillo, M., Marquez-Ruiz, G., Dobarganes, M.C. (2004) Oxidative stability of sunflower oils differing in 
unsaturation degree during long-term storage at room temperature. Journal of the American Oil Chemists Society, 81 , 577-583.

Merrill, L.I., Pike, O.A., Ogden, L.V. (2008) Oxidative Stability of Conventional and High-Oleic Vegetable Oils with Added Antioxidants. Journal of the American Oil Chemists Society, 85, 771-776.

Oomah, B.D., Liang, L., Godfrey, D., Mazza, G. (1998) Microwave heating of grapeseed: effect on oil quality. Journal of Agricultural and Food Chemistry, 46, 4017-4021.

Pan, Y., Zhang, X., Wang, H., Liang, Y., Zhu, J., Li, H., Zhang, Z., Wu, Q. (2007) Antioxidant potential of ethanolic extract of Polygonum cuspidatum and application in peanut oil. Food Chemistry, 105, 1518-1524. 189.

Rovellini, P., Cortesi, N., Fedeli, E. (1997) Ossidazioni dei lipidi. Nota 1. Rivista Italiana delle Sostanze Grasse 74, 181-

Salvador, M.D., Aranda, F., Gomez-Alonso, S., Fregapane, G. (2001) Cornicabra virgin olive oil: a study of five crop seasons. Composition, quaility and oxidative stability. Food chemistry, 74, 267-274.

Shahidi, F. (2005) Bailey's Industrial Oil \& Fat Products (Sixth edition), Volume 1, Edible Oil \& Fat Products:Chemistry, Properties and Health Effects, Eiley-Interscience publication: 269-513.

Suja, K.P., Abraham, J.T., Thamizh, S.N., Jayalekshmy, A., Arumughan, C. (2004) Antioxidant efficacy of sesame cake extract in vegetable oil protection. Food Chemistry, 84, 393-400.

Sumnu, G. (2001) A review on microwave bakin gof foods. Int. J. Food Sci. Technol., 36: 117-127.

Taghvaei, M., Jafari, S.M. (2013) Application and stability of natural antioxidants i edible oils in order to substitute synthetic additives. J. Food Sci. Technol., 52, 1272-1282.

Teh, S.S., Birch, J. (2013) Physicochemical and quality characteristics of cold-pressed hemp, flax and canola seed oils. J. Food Compos. Anal., 30, 26-31.

Velasco, J., Dobarganes, C. (2002) Oxidative stability of virgin olive oil. Eur. J. Lipid Sci. Technol., 104, 661-676.

Zunin, P., Leardi, R., Bisio, A., Boggia, R., Romussi, G. (2010) Oxidative stability of virgin olive oil enriched with carnosic acid. Food Research International, 43 (5), 1511-1516.

Prispjelo/Received: 4.10 .2018

Prihvaćeno/Accepted: 16.10.2018.

\title{
The Influence of Microwave Heating and Addition of Antioxidants on the Shelf life of Ekstra Virgin Olive Oil variety Oblica
}

\begin{abstract}
Virgin olive oil has a high resistance to oxidative deterioration due to both a triacylglycerol composition low in polyunsaturated fatty acids and a group of phenolic antioxidants composed mainly of polyphenols and tocopherols. This essay discusses the effect of microwave heating on the oxidative stability of extra virgin olive oil with or without the addition of antioxidants and synergists. Of natural antioxidants are used rosemary extract and green tea extract and citric acid synergist. Oil samples with or without the addition of antioxidants and synergists were heated in a microwave oven at a constant power of $300 \mathrm{~W}$ over a different time period (5, 10, 15 and 20 minutes). Samples were also heated at different power levels $(180,300,450 \mathrm{~W})$ in a constant time period of 5 minutes. The result of the accelerated oxidation test of olive oil is expressed by the peroxide number. Microwave heating of the samples during a longer heating time increases the temperature and the value of the peroxide number, which results in an increase in oxidative oil degradation. Addition of antioxidants and synergists increased the stability of olive oil. The highest stability of extra virgin olive oil was achieved by a combination of green tea extract and synergistic citric acid.
\end{abstract}

Key words: extra virgin olive oil, microwave heating, oxidation stability, antioxidants, synergists 